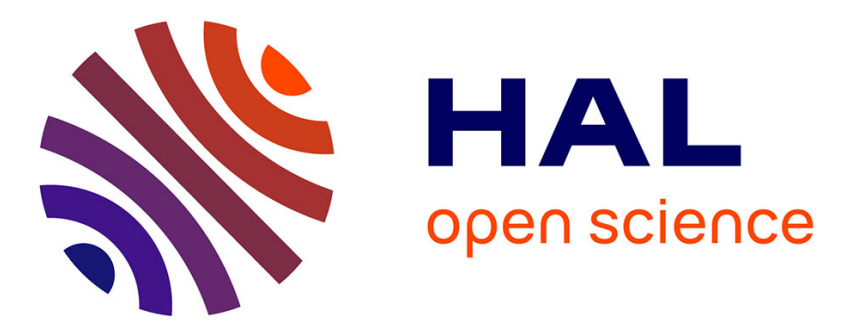

\title{
Optimal Operation Strategies of Compressed Air Energy Storage (CAES) on Electricity Spot Markets with Fluctuating Prices
}

\author{
Henrik Lund, Georges Salgi, Brian Elmegaard, Anders N. Andersen
}

\section{- To cite this version:}

Henrik Lund, Georges Salgi, Brian Elmegaard, Anders N. Andersen. Optimal Operation Strategies of Compressed Air Energy Storage (CAES) on Electricity Spot Markets with Fluctuating Prices. Applied Thermal Engineering, 2010, 29 (5-6), pp.799. 10.1016/j.applthermaleng.2008.05.020 . hal-00630270

\author{
HAL Id: hal-00630270 \\ https://hal.science/hal-00630270
}

Submitted on 8 Oct 2011

HAL is a multi-disciplinary open access archive for the deposit and dissemination of scientific research documents, whether they are published or not. The documents may come from teaching and research institutions in France or abroad, or from public or private research centers.
L'archive ouverte pluridisciplinaire HAL, est destinée au dépôt et à la diffusion de documents scientifiques de niveau recherche, publiés ou non, émanant des établissements d'enseignement et de recherche français ou étrangers, des laboratoires publics ou privés. 


\section{Accepted Manuscript}

Optimal Operation Strategies of Compressed Air Energy Storage (CAES) on Electricity Spot Markets with Fluctuating Prices

Henrik Lund, Georges Salgi, Brian Elmegaard, Anders N. Andersen

PII:

S1359-4311(08)00246-9

DOI:

10.1016/j.applthermaleng.2008.05.020

Reference:

ATE 2523

To appear in:

Applied Thermal Engineering

\section{APPLIED}

THERMAL

ENGINEERING

29 January 2008

Received Date:

29 April 2008

Revised Date:

20 May 2008

Accepted Date:

Please cite this article as: H. Lund, G. Salgi, B. Elmegaard, A.N. Andersen, Optimal Operation Strategies of Compressed Air Energy Storage (CAES) on Electricity Spot Markets with Fluctuating Prices, Applied Thermal Engineering (2008), doi: 10.1016/j.applthermaleng.2008.05.020

This is a PDF file of an unedited manuscript that has been accepted for publication. As a service to our customers we are providing this early version of the manuscript. The manuscript will undergo copyediting, typesetting, and review of the resulting proof before it is published in its final form. Please note that during the production process errors may be discovered which could affect the content, and all legal disclaimers that apply to the journal pertain. 


\title{
Optimal Operation Strategies of Compressed Air Energy Storage (CAES) on Electricity Spot Markets with Fluctuating Prices
}

\author{
Henrik Lund $^{\mathrm{a}, *}$, Georges Salgi ${ }^{\mathrm{a}}$, Brian Elmegaard ${ }^{\mathrm{b}}$ and Anders N. Andersen ${ }^{\mathrm{c}}$ \\ ${ }^{a}$ Department of Development and Planning, Aalborg University, Fibigerstraede 13, DK-9220, Denmark \\ ${ }^{\mathrm{b}}$ Department of Mechanical Engineering, Technical University of Denmark, Kgs. Lyngby \\ ${ }^{\mathrm{c}}$ EMD International A/S, NOVI, Aalborg, Denmark
}

\begin{abstract}
Compressed Air Energy Storage (CAES) technologies can be used for load levelling in the electricity supply and are therefore often considered for future energy systems with a high share of fluctuating renewable energy sources, such as e.g. wind power. In such systems, CAES plants will often operate on electricity spot markets by storing energy when electricity prices are low and producing electricity when prices are high. In order to make a profit on such markets, CAES plant operators have to identify proper strategies to decide when to sell and when to buy electricity. This paper describes three independent computer-based methodologies which may be used for identifying the optimal operation strategy for a given CAES plant, on a given spot market and in a given year. The optimal strategy is identified as the one which provides the best business-economic net earnings for the plant. In practice, CAES plants will not be able to achieve such optimal operation, since the fluctuations of spot market prices in the coming hours and days are not known. Consequently, two simple practical strategies have been identified and compared to the results of the optimal strategy. This comparison shows that, in practice, a CAES plant can be expected to earn 80-90 per cent of the optimal earnings.
\end{abstract}

Keywords: CAES, Compressed Air Energy Storage, Energy System analysis, Electricity market optimisation

\section{List of Symbols and Abbreviations}

- CAES: Compressed Air Energy Storage

- CHP: Combined Heat and Power

- GT: Gas Turbine

- $\eta_{\mathrm{c}}$ : Compressor efficiency

- $\eta_{\mathrm{t}}$ : Turbine storage efficiency

- $\eta_{\text {ratio }}$ Fuel ratio

- $\mathrm{P}_{\text {Ngas }}$ : Average annual natural gas price

- $\quad \mathrm{P}_{\text {buy }}$ : Hourly price of the electricity bought for the compressor.

- $\mathrm{P}_{\text {sell }}$ : Hourly sales price of the electricity produced by the turbine

- MAXhour: Hour with maximum electricity price in the annual time series

- $\quad \mathrm{MC}_{\mathrm{c}}$ : Variable operational cost of the compressor

- $\quad \mathrm{MC}_{\mathrm{t}}$ : Variable operational cost of the turbine

- $\mathrm{MC}_{\text {prod}}$ : Marginal cost of producing one unit of electricity

Corresponding author. Tel.: +45 9940 8309; fax: +45 98153788.

E-mail address: Lund@plan.aau.dk 


\section{Introduction}

Compressed air energy storage (CAES) is a modification of the basic gas turbine (GT) technology, in which off-peak electricity is used for storing compressed air in an underground cavern. This air is then heated and expanded in a gas turbine to produce electricity during peak demand hours. As it derives from GT technology, CAES technology is readily available and reliable. Two plants have been constructed in the world so far; one in Germany and one in the USA of 390 MW and 110 MW turbine capacities, respectively. How to design and use CAES for load levelling in the electricity supply has been analysed and discussed for several decades in academic literature [1-4]. In recent years, CAES has primarily been seen as a means of improving the integration of fluctuating wind power into the electricity supply [5-9] or it has been compared to other electricity storage options $[10,11]$. However, so far the optimisation of CAES operation on electricity spot markets has not been dealt with.

The need for electricity storage technologies, such as CAES plants, increases along with the share of fluctuating renewable energy sources and other units with production restrictions, like e.g. combined heat and power production (CHP). Due to a long period of active energy policy, Denmark has become a front runner in terms of energy supply [12-15]. At present, the wind power share is 20 per cent and CHP meets 50 per cent of the electricity demand. Consequently, a number of different technologies have been analysed and considered in the Danish system [16-21] and by year 2004, it was decided to change the regulation of distributed CHP plants. Such plants used to be operated by applying a fixed triple tariff. However, they are now operated according to the terms on the Nordic electricity market, where electricity price variations reflect the actual production of wind and other sources. Consequently, the optimisation strategies for such CHP market operation have been developed and discussed [22,23]. If CAES technologies are to become part of the energy system, such plants will have to operate on the same market. However, so far proper market optimisation strategy tools have not been developed for CAES plants.

This paper is divided into two main sections. The first section aims at identifying the theoretical maximum net operational profit of a specified CAES plant given deterministic electricity system prices. This optimisation problem is approached from three different perspectives, and the results are compared in order to ensure their uniqueness. In practice, however, CAES plants are not able to achieve such optimal operation, since the fluctuations of spot market prices in the coming hours and days are not known. Consequently, two simple practical strategies have been identified and compared to the results of the optimal strategy. The optimisation does not directly take into account the extra ancillary service payments that a CAES plant can achieve. However, by using historical regulating market prices along with the corresponding regulating power demand time series, the potential extra income can be estimated.

A simple mathematical model for the CAES plant was developed for the optimisations. In this model, the operations of the individual compressor and turbine units were described using isentropic efficiencies. In addition to the compressor, turbine, and storage capacities, three main performance indicators were used to describe the performance of the plant:

- The compressor efficiency $\left(\eta_{\mathrm{c}}\right)$ defined as the energy storage input divided by the power input to the compressor 
- The turbine storage efficiency $\left(\eta_{t}\right)$ defined as the power output of the turbine divided by the energy storage output.

- The fuel ratio ( $\eta_{\text {ratio }}$ ) defined as the fuel input to the turbine per electricity output

The plant model permits the simultaneous operation of the compressor and the turbine, a phenomenon that can be economically feasible from an operational point of view, especially when electricity prices are high (See fig 1). This, however, does not take into account the extra investment costs related to the simultaneous operation.

\section{Optimal Operation Strategy Methodologies}

The optimal operation strategy has been identified by using the following three independent computer-based tools and methodologies:

- Dynamic programming

- energyPRO software designed for business-economic operation of single plants (CHP etc.)

- EnergyPLAN software designed for energy market system analysis of national energy systems

\subsection{Dynamic programming}

Dynamic programming is a well-known mathematical method for optimisation of separable problems. It is well suited for the optimisation of nonlinear problems with a relatively low number of constraints. In the present case, the prerequisites for the method are fulfilled and the method has been applied in order to find the best operation strategy for the defined CAES plant.

The actual implementation of the method is done by defining one or more initial charges of the storage and requiring the same storage level at the end of the optimisation period. For each hour of the year, the method proceeds to find the best operation strategy. It selects the possible operating modes in order to reach the possible charges at the next hour. If the storage reservoir is not close to being either full or empty, four operation modes are possible:

1. No operation at no net income and no storage level change

2. Compressor operation at a negative net income equal to the electricity cost at the given hour and an increased storage level

3. Turbine operation at a net income of the electricity cost minus the natural gas cost and a decreased storage level

4. Simultaneous operation of compressor and turbine at a net income of the net electricity cost minus the gas cost and no storage level change

If the storage is close to a limit, neither mode 2 nor 3 will be possible solutions.

At the next hour, a number of storage charges can be reached. Each of these levels may be reached from one or more of the charges at the present hour. The net income of each of the possible charges is calculated and the best obtainable net income, which stays at this level during the next hour, is stored. For each possible storage level at each hour, the only information that needs to be stored is the best net income and the operating mode used in order to reach this level. The complete optimisation method has been implemented in Python (www.python.org) in less than 100 lines of code. 
During operation, the store pressure will vary and the compressor and turbine may experience off-design operation conditions. However, in the present study, the efficiency of the machines is assumed to be constant. This is considered a valid approach as the overall pressure ratio does not change considerably. The compressor train is divided into several stages of intercooling in such way that each compressor will operate close to the design point. The turbine will always operate at its design point as the inlet is throttled to have a constant inlet pressure. Calculations in [24] show that the efficiency of the turbine process is not significantly decreased due to the throttling.

\subsection{Energy plant operation and design tool (energyPRO)}

The energyPRO is a modelling software package used for the combined technoeconomic design, analysis and optimisation of plants. Cogeneration and trigeneration as well as other types of complex energy projects involving energy storages can be modelled in energyPRO. The method for calculating the optimal operation of CAES plants in energyPRO is illustrated by a CAES plant operated according to spot prices in Western Denmark in 2003.

In an energyPRO market optimisation, the market prices of an entire year are divided into an unlimited number of market price intervals, each interval containing a number of hours at which the spot prices are situated. In the Operation strategy window, you will find a matrix showing the names of the production units vertically and the names of the market price intervals horizontally. You put in priority numbers in this matrix in order to determine in which order the production units shall produce.

The mathematical solver in energyPRO will test all available possibilities for a production unit to produce at hours and within a certain price interval, taking into account all restrictions in demand and energy storage. Then, it will continue to test productions of lower priority. One should keep in mind that productions in this way are planned non-chronologically, making it necessary for the energyPRO to conduct thorough controls and make sure that new productions do not disturb future and already planned productions.

When optimising a CAES plant in energyPRO, this non-chronological way of planning is used in an indirect manner. The compressor is divided into two production units, "Compressor operation" and "CANCEL compressor operation". The production unit "Compressor operation" is given top priority. This has the effect that the compressor is assumed to be running at all hours of the year producing compressed air to the storage.

When the production unit "CANCEL compressor operation" is brought into effect, it consumes exactly the amount of compressed air produced by the compressor. This means that when activating the "CANCEL compressor operation" unit in a certain time period, the compressor does not operate during that period.

The order in which the turbine and the "CANCEL compressor operation" unit shall be operated in the different market price intervals is found from the marginal production cost graph in Fig. 2. An example of this order would be as follows: Before the turbine produces at a market price of 200 DKK/MWh, the "CANCEL compressor operation" unit must be activated at market prices above $80 \mathrm{DKK} / \mathrm{MWh}$. This sequence will make 
sure that the compressed air used by the turbine at a market price of $200 \mathrm{DKK} / \mathrm{MWh}$ originates from the compressor when prices are above $80 \mathrm{DKK} / \mathrm{MWh}$.

\subsection{Energy system analysis tool (EnergyPLAN)}

The EnergyPLAN model is a general energy system analysis tool designed for the analysis of regional or national energy systems. It is an input-output model. Inputs are data on capacities and efficiencies of the energy-converting units of the system as well as available fuels and renewable energy sources. Hour by hour the model calculates how the electricity and heat demands of the complete system will be met under the given constraints and regulation strategies. The model concentrates on the electrical system but it also incorporates other parts which interact with this system. The result of the calculation is a detailed knowledge on the production of the different units. From this, fuel consumption can be calculated. Subsequently, the socio-economic costs and $\mathrm{CO}_{2}$ emissions of a production meeting the demands of society can be found. The model has previously been used in a number of energy system analysis activities, including expert committee work for the Danish Authorities [25], and the design of 100 per cent renewable energy systems [26]. More information on the model can be found in [27,28]. The present version 7.0 of the EnergyPLAN model including documentation can be downloaded free of charge from the following home page: www.EnergyPLAN.eu.

In general, the EnergyPLAN model has a focus on system analysis, i.e. the analysis of national or regional energy systems. However, the model also enables a businesseconomic analysis of individual plants in the case of electricity storage systems with a special focus on CAES plants. The methodology used for identifying the optimal operation strategy is the following:

The key principle is based on the fact that in order to make a profit the market price of selling, $\mathrm{P}_{\text {sell, }}$ has to be higher than the marginal cost of producing one unit of electricity, $\mathrm{MC}_{\text {prod: }}$

$$
\mathrm{MC}_{\text {prod }}<\mathrm{P}_{\text {Sell }}
$$

The marginal production cost is defined by the marginal operation cost, the natural gas price and the price of buying electricity for the compressor. $\mathrm{MC}_{\text {prod }}$, is found by applying the following formula:

$$
\mathrm{MC}_{\text {prod }}=\mathrm{P}_{\text {Ngas }} \cdot \eta_{\text {ratio }}+\mathrm{MC}_{\mathrm{t}}+\left[\left(\mathrm{P}_{\text {buy }}+\mathrm{MC}_{\mathrm{c}}\right) /\left(\eta_{\mathrm{c}} \cdot \eta_{\mathrm{t}}\right)\right]
$$

\section{Where:}

- $\eta_{\mathrm{c}}$ is the compressor efficiency

- $\eta_{\mathrm{t}}$ is the turbine storage efficiency defined as the power output per unit of energy storage input.

- $\eta_{\text {ratio }}$ is the fuel ratio defined as the fuel input to the turbine per electricity output

- $\mathrm{MC}_{\mathrm{c}}$ is the variable operational cost of the compressor

- $\quad \mathrm{MC}_{\mathrm{t}}$ is the variable operational cost of the turbine

- $\quad P_{\text {Ngas }}$ is the average annual natural gas price

- $\quad \mathrm{P}_{\text {buy }}$ is the average hourly electricity price for the compressor. 
At some hours with very high electricity prices, it sometimes pays to bypass the storage while operating the compressor and the turbine at the same time. Such operation is included in the strategy and allows the compressor and turbine to operate simultaneously during the same hour, in case the storage reservoir is empty.

The optimal operation strategy aims at finding the maximum theoretical operational income given a deterministic annual electricity price time series. The algorithm can be summarised by repeating the following 7 steps:

1) Identify the hour of the maximum electricity price (MAXhour) in the spot market price series. Such hour is given priority when operating the turbine. (In the following iterations, hours already identified are disregarded and the hour of the remaining maximum price is picked).

2) Identify the storage boundaries around MAXhour. Running the turbine at MAXhour will have to be compensated for by running the compressor in such a way that the storage boundaries are not compromised. In this step, the hours before and after MAXhour are examined. In the time period after MAXhour, the storage has to be charged before the storage reservoir is empty. Similarly, in the time period before MAXhour, the storage reservoir has to be charged after it is full. Consequently, the period between the last hour of full storage before MAXhour and the first hour of empty storage after MAXhour is identified. This range constitutes the time space in which recharging/discharging is possible. The range can very well constitute only the MAXhour itself, in which case the plant may operate in the bypass mode.

3) Identify the minimum electricity price within the range defined in step 2 . Such hour is given priority when operating the compressor. (In the following iterations, hours already identified are disregarded and the hour of the remaining minimum price is picked).

4) Calculate the marginal operating cost $\left(\mathrm{MC}_{\text {prod }}\right)$ based on the minimum price $\left(\mathrm{P}_{\text {buy }}\right)$ found in step 3. The marginal production cost $\left(\mathrm{MC}_{\text {prod }}\right)$ is calculated according to the equation described above. If the maximum electricity price $\left(\mathrm{P}_{\text {sell }}\right)$ found in step 1 is higher than the marginal production cost $\left(\mathrm{MC}_{\text {prod }}\right)$, the calculation proceeds to step 5 .

5) Determine the "operation bottlenecks" in the range between the maximum and minimum prices. In the case that one hour of compressor operation is compensated for by exactly one hour of turbine operation there is no bottleneck. Otherwise, the turbine and/or the compressor may have to partly load and the bottleneck is identified as the minimum of the following 4 considerations:

a. Available turbine capacity at the maximum price hour.

b. Available compressor capacity at the minimum price hour.

c. The minimum free storage space if the compressor operation takes place before the turbine operation.

d. The minimum storage content in case the compressor operation succeeds the turbine operation. 
6) Operate the turbine at the hour of maximum price and the compressor at the hour of minimum price by the capacity determined in step 5 and update the storage content. In case the turbine has reached its full capacity, the hour is disregarded in the following iterations. Similarly, in case the compressor has reached its full capacity.

7) Iterate back to step 1 until the period of one year is completed.

To illustrate the algorithm of the strategy, an example is shown in figure 3 for a CAES plant comprised by a $216 \mathrm{MW}$ compressor, a $360 \mathrm{MW}$ turbine and a $1478 \mathrm{GWh}$ storage. In such system, the rates of air compression and expansion are equal. This permits an equal number of compression and expansion hours, and such case is presented here for illustration purposes. The algorithm is, however, capable of dealing with unequal compression and expansion rates.

Figure 3 shows the Nord Pool 2005 electricity prices (upper diagram) used in the simulation of the CAES plant operation during various iterations (the next three diagrams). After the first iteration, it is seen that the maximum price is reached around hour 4000, and the turbine is operated during that hour. The compressor is operated during the minimum price hour (in this case hour 32) within the time range that does not violate the storage constraint (in this case all hours before hour 4000).

After 18 iterations (next diagram), the turbine is operated at the 18 hours with the highest prices, while the compressor operates at the 18 hours with the lowest prices. In year 2005, the lowest price hours are concentrated at the beginning of the year.

After 100 iterations (last diagram), the CAES plant operation is distributed over the year as the price maximums and minimums are utilised. Note the correlation between the operation hours and the electricity prices at the top of the figure. The simulation continues until all hours with feasible operation prices are utilised.

As can be seen, the EnergyPLAN algorithm permits partial load operation. However, in most cases part load can be implemented as full load in part time. If e.g. the turbine is operated in three full load hours followed by 50 percent part load in one hour, the same income can be achieved by operating the turbine full load during three and half an hour.

\section{Practical operation strategies}

In practice, CAES plants will not be able to implement the above-mentioned optimal operation strategies, since the fluctuations of spot market prices in the coming hours and days are not known for a whole year. However, the EnergyPLAN model includes two additional strategies, which can be implemented:

- Practical historical strategy, in which decisions on buying and selling electricity are solely based on the knowledge of the average price of a certain historical period, e.g. 24 hours;

- Practical prognostic strategy, in which buying and selling electricity are based on the average price of the coming e.g. 24 hours. Such a strategy requires the presence of good price prognoses.

The concept behind the prognostic strategy is to take the average price of an upcoming user-specified period and bid on the market correspondingly. The bid on the market 
occurs in such way that the price difference between the buying and bidding prices is equally distributed around the average price. Figure 4 demonstrates this concept for a 24-hour period. The centre line represents the price average for the shown 24 hourperiod. Based on that, the distances to the two other lines are calculated.

The distance between the minimum/maximum lines and the average price, $\Delta \mathrm{P}$, can be calculated analytically using the following equation:

$$
\Delta P=\frac{\bar{P}\left(1-\eta_{C} \eta_{T}\right)+K}{1+\eta_{C} \eta_{T}}
$$

Where $\bar{P}$ is the average price over the given period and $\mathrm{K}$ is a constant that includes the variable operational costs and fuel costs:

$$
\mathrm{K}=\mathrm{MC}_{\mathrm{c}}+\eta_{\mathrm{c}} \eta_{\mathrm{t}}\left(\eta_{\text {ratio }} \cdot \mathrm{P}_{\text {Ngas }}+\mathrm{MC}_{\mathrm{t}}\right)
$$

It is noted here that the price average, $\bar{P}$, is a flexible average and is updated on an hourly basis, as opposed to a fixed average over the specified period. This implicitly assumes the ability of the system operator to update market bids on an hourly basis. Again, the bypass of the storage at hours with very high electricity prices is included in the strategy, and allows the compressor and turbine to operate simultaneously during the same hour in case the storage reservoir is empty.

The practical historical strategy is similar to the prognostic strategy with the only difference that the average price is based on the previous 24 hours instead of a price prognosis for the upcoming hours.

\section{Results}

The three different methodologies for identifying optimal operation have been tested on the CAES plant defined in table 1. Such plant represents "state-of-the-art" technology. The compressor and turbine capacities correspond to an air flow of 400 $\mathrm{Kg} / \mathrm{s}$. The storage size is based on a $700,000 \mathrm{~m}^{3}$ cavern operating between 60 bars and 80 bars [24] at an average wall temperature of $35^{\circ} \mathrm{C}$ [29].

The marginal operation costs are based on typical variable costs of running turbines and compressors. The number of start-ups has been taken into account. Typically, the identified strategies show an average annual number of start-ups below 1 start/day. To some extent, the variable costs include maintenance costs, since such costs depend on the equivalent number of operational hours.

For the reference year of 2003, the average annual price of German natural gas is approximately $92 \mathrm{DKK} / \mathrm{MWh}$. For simplicity and as the price tends to increase, it is chosen to use the price of $100 \mathrm{DKK} / \mathrm{MWh}$ (equal to approximately $13 \mathrm{EUR} / \mathrm{MWh}$ ).

With regard to the choice of spot market electricity prices, the consideration has been to choose a challenging year in terms of model performance. When comparing the system prices in Western Denmark as part of the North Pool market for the years 2000 2005, it is seen that the year 2003 contains various price trends including sharp peaks and low prices reaching down to $0 \mathrm{kr} / \mathrm{MWh}$ (Figure 5). Thus, the volatility of the prices in 2003 is high compared to other years. It was therefore chosen to use the system prices of Western Denmark of 2003 in the base scenario. 
The annual results of running the three models are shown in table 2. As seen, all models come to exactly the same results. It should be noted, however, that the input numbers have been adjusted slightly in order to achieve exactly the same results in such detail. First, the capacities were chosen on the assumption that full hours of compression and expansion are needed in order to completely fill or empty the storage. This permits a comparison between the models, where the dynamic programming algorithm permits partial load operation, as mentioned earlier. Consequently, the input efficiencies have been expressed in many decimals in order to meet this assumption. Secondly, as described before, the energyPRO model makes use of price intervals, and in order to identify such price intervals without defining too many, the input spot market prices have been rounded to integer. However, with these small adjustments, as shown, the three models come to exactly the same results when based on exactly the same inputs.

When comparing the results on an hourly basis, it can be seen that the results revolved around the same optimal solution. The only difference is that, in series of hours with exactly the same price (which is the case in 2003 for the price level zero), the three models choose to fill the storage at different hours. However, in the end, the solutions are exactly the same.

In table 3, the two practical optimisation strategies are compared to the theoretically optimal strategy. As one can see, the practical historical strategy results in a net earning of approximately 80 per cent and the prognostic strategy in approximately 90 per cent of the optimal earnings. It should, however, be emphasised that the results do depend on the specific price variations of the specific year. Additional analyses on historical spot market prices in the period from 2001-2006 demonstrate that the annual net earnings vary significantly between the years. Still such analyses show that the practical net earnings are likely to be in the range of 80 to 90 per cent compared to the optimal earnings [30].

\section{Conclusion}

Compressed Air Energy Storage technologies can be used for electricity balancing in future energy systems with a high share of fluctuating renewable energy sources such as e.g. wind power. In such systems, CAES plants will often operate on electricity spot markets by storing energy when electricity prices are low and producing electricity when prices are high. In order to make a profit on such markets, CAES plant operators have to identify proper strategies to decide when to sell and when to buy electricity. This paper has described three independent computer-based methodologies for identifying the optimal operation strategy for a given CAES plant, on a given spot market and in a given year. The optimal strategy is defined as the one which will provide best business-economic net earnings for the plant. Applied to a specific CAES plant following the spot market prices of Western Denmark on the Nord Pool market in 2003, all three methodologies have identified the same operation strategy as the optimal one.

In practice, CAES plants will not be able to achieve such optimal operation, since the fluctuations of spot market prices in the coming hours and days are not known. Consequently, two simple practical strategies have been identified. Both strategies are based on an estimate of the average price and a calculation of the price difference 
required between buying and selling electricity in order to make a profit. The plant efficiencies and the natural gas price are taken into consideration in this calculation. In one strategy (historical), the estimate of the average price is simply made on the basis of the price during the former 24 hours. In the other (prognostic), the average is calculated on the basis of a good price prognosis. The results of the two practical strategies have been compared to the results of the optimal strategy showing that, in practice, a CAES plant is likely to be able to earn 80-90 per cent compared to the optimal earnings.

\section{Acknowledgements}

The work presented in this paper is the result of a research project partly financed by the Danish Transmission System Operator, Energinet.dk. Moreover, DONG Energy has participated in the project. We wish to thank especially Axel Hauge Pedersen from DONG Energy as well as Henning Parbo and Kim Benche from Energinet.dk for sharing information and making helpful comments on the work.

\section{References}

[1] A Sharma, HH Chiu, FW Ahrens, RK Ahluwalia, KM Ragsdell. Design of optimum compressed air energy-storage systems, Energy. 4 (1979) 201-216.

[2] AJ Giramonti, RD Lessard, WA Blecher, EB Smith. Conceptual design of compressed air energy storage electric power systems, Appl.Energy. 4 (1978) 231-249.

[3] D Weiner. Dynamic optimization for operation of a compressed air energy storage system, Journal of Dynamic Systems, Measurement and Control, Transactions ASME. 111 (1989) 112-114.

[4] K Yoshimoto, T Nanahara. Optimal daily operation of electric power systems with an ACC-CAES generating system, Electrical Engineering in Japan. 152 (2005) 15-23.

[5] A Cavallo. Controllable and affordable utility-scale electricity from intermittent wind resources and compressed air energy storage (CAES), Energy. 32 (2007) 120-127.

[6] JB Greenblatt, S Succar, DC Denkenberger, RH Williams, RH Socolow. Baseload wind energy: modeling the competition between gas turbines and compressed air energy storage for supplemental generation, Energy Policy. 35 (2007) 1474-1492. 
[7] P Denholm. Improving the technical, environmental and social performance of wind energy systems using biomass-based energy storage, Renewable Energy. 31 (2006) $1355-1370$.

[8] DJ Swider. Compressed air energy storage in an electricity system with significant wind power generation, IEEE Trans.Energy Convers. 22 (2007) 95-102.

[9] G Salgi, H Lund. System behaviour of compressed-air energy-storage in Denmark with a high penetration of renewable energy sources, Appl.Energy. 85 (2008) 182-189.

[10] P Denholm, GL Kulcinski. Life cycle energy requirements and greenhouse gas emissions from large scale energy storage systems, Energy Conversion and Management. 45 (2004) 2153-2172.

[11] S van der Linden. Bulk energy storage potential in the USA, current developments and future prospects, Energy. 31 (2006) 3446-3457.

[12] F Hvelplund. Renewable energy and the need for local energy markets, Energy. 31 (2006) 2293-2302.

[13] H Lund. A green energy plan for Denmark - Job creation as a strategy to implement both economic growth and a CO2 reduction, Environ.Resour.Econ. 14 (1999) 431-439.

[14] H Lund. Choice Awareness: The Development of Technological and Institutional Choice in the Public Debate of Danish Energy Planning, J.Environ.Policy Plann. 2: (2000) 249-259.

[15] H Lund, E Münster. Integrated energy systems and local energy markets, Energy Policy. 34 (2006) 1152-1160.

[16] BV Mathiesen, H Lund. Relocation technologies for integration of fluctuating renewable energy sources, Submitted for Energy Conversion and Management. (2008).

[17] M Münster. Use of Waste for Heat, Electricity and Transport - Challenges when performing Energy System Analysis, Proceedings from 4th Dubrovnik Conference on Sustainable Development of Energy, Water and Environment Systems. Dubrovnik, Croatia. (2007).

[18] BV Mathiesen, H Lund, P Nørgaard. Integrated transport and renewable energy systems, Utilities Policy. uncorrected proof (2008).

[19] M Blarke, H Lund. Large-Scale Heat Pumps In Sustainable Energy Systems: System And Project Perspectives, Journal of Thermal Science. 11 (2007) 141-152.

[20] H Lund, E Münster. Integrated transportation and energy sector CO2 emission control strategies, Transport Policy. 13 (2006) 426-433.

[21] H Lund. Large-scale integration of optimal combinations of PV, wind and wave power into the electricity supply, Renewable Energy. 31 (2006) 503-515. 
[22] AN Andersen, H Lund. New CHP partnerships offering balancing of fluctuating renewable electricity productions, J.Clean.Prod. 15 (2007) 288-293.

[23] H Lund, AN Andersen. Optimal designs of small CHP plants in a market with fluctuating electricity prices, Energy Conversion and Management. 46 (2005) 893-904.

[24] B Elmegaard, N Szameitat, W Brix. Compressed-air energy-storage (CAES) Possibilities in Denmark, Proceedings of ECOS 2005. (2005).

[25] H Lund, E Münster. Management of surplus electricity-production from a fluctuating renewable-energy source, Appl.Energy. 76 (2003) 65-74.

[26] H Lund. Renewable energy strategies for sustainable development, Energy. 32 (2007) 912-919.

[27] H Lund, E Münster. Modelling of energy systems with a high percentage of CHP and wind power, Renewable Energy. 28 (2003) 2179-2193.

[28] H Lund, EnergyPLAN Advanced Energy System Analysis Model, Aalborg University, www.energyPLAN.eu, Denmark, 2007.

[29] F Crotogino, K- Mohmeyer, R Scharf. Huntorf CAES/more than 20 years of successful operation, SMRI Spring Meeting. (2001).

[30] H Lund, G Salgi. The Role of Compressed Air Energy Storage (CAES) in Future Sustainable Energy Systems, Energy Conversion and Management. Submitted (2008). 


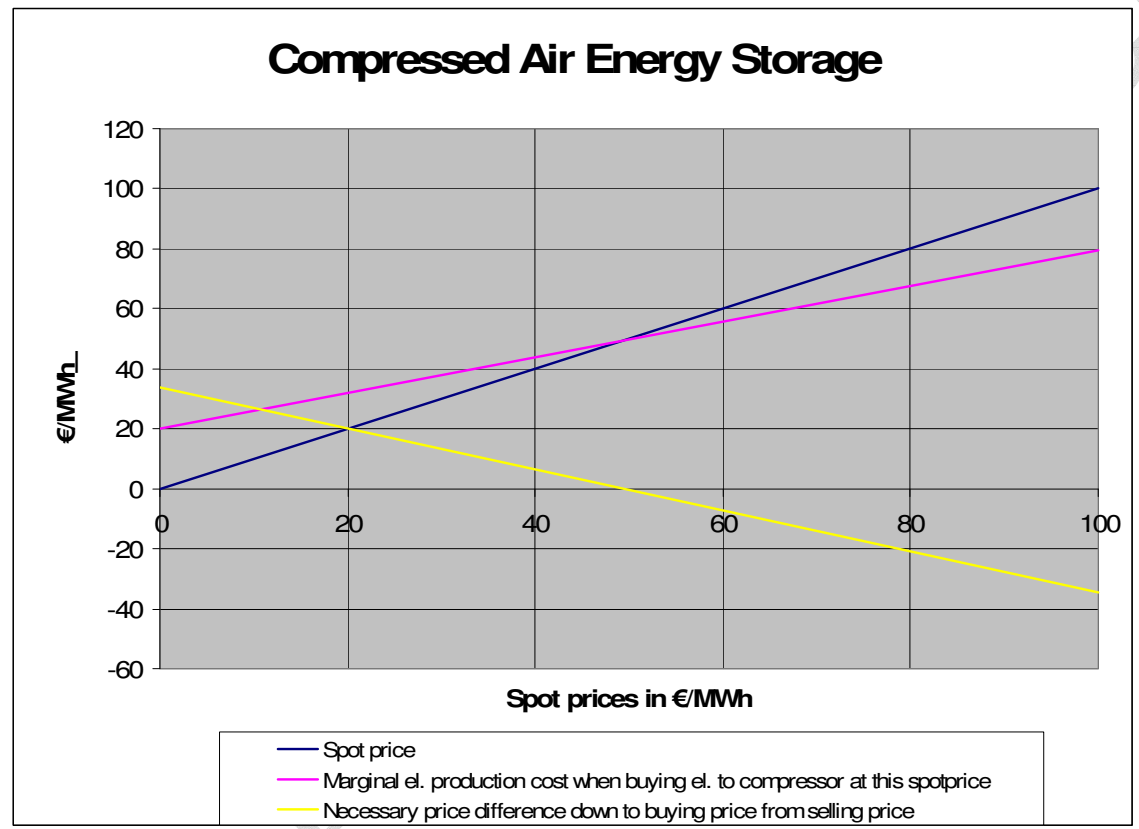

Figure 1: Marginal production cost for $1 \mathrm{MWh}$ of electricity from the turbine seen as a function of the buying price of electricity for the compressor. 


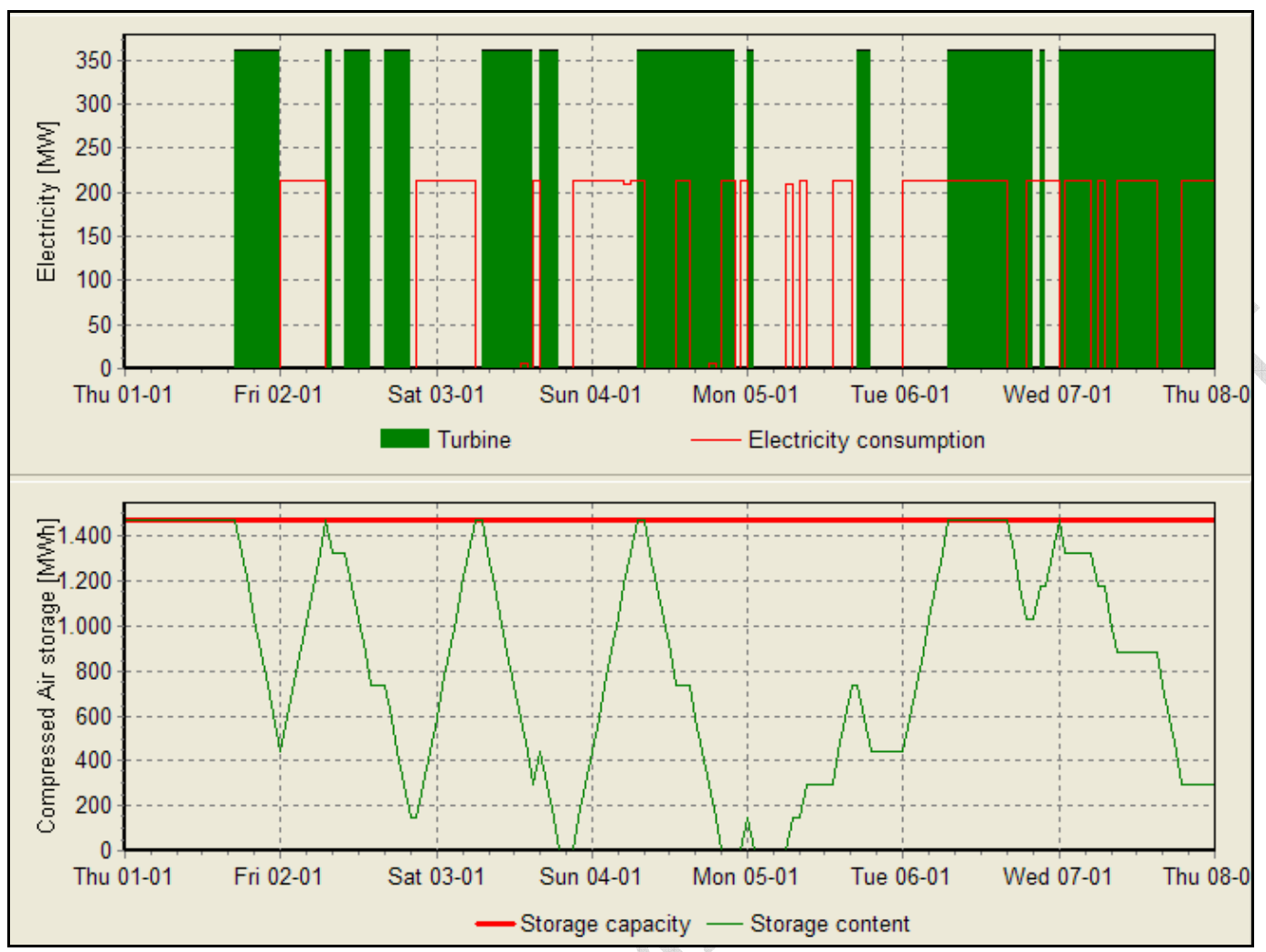

Figure 2: Energy conversion 7 days in January. At some hours, both the turbine and the compressor are operated. 

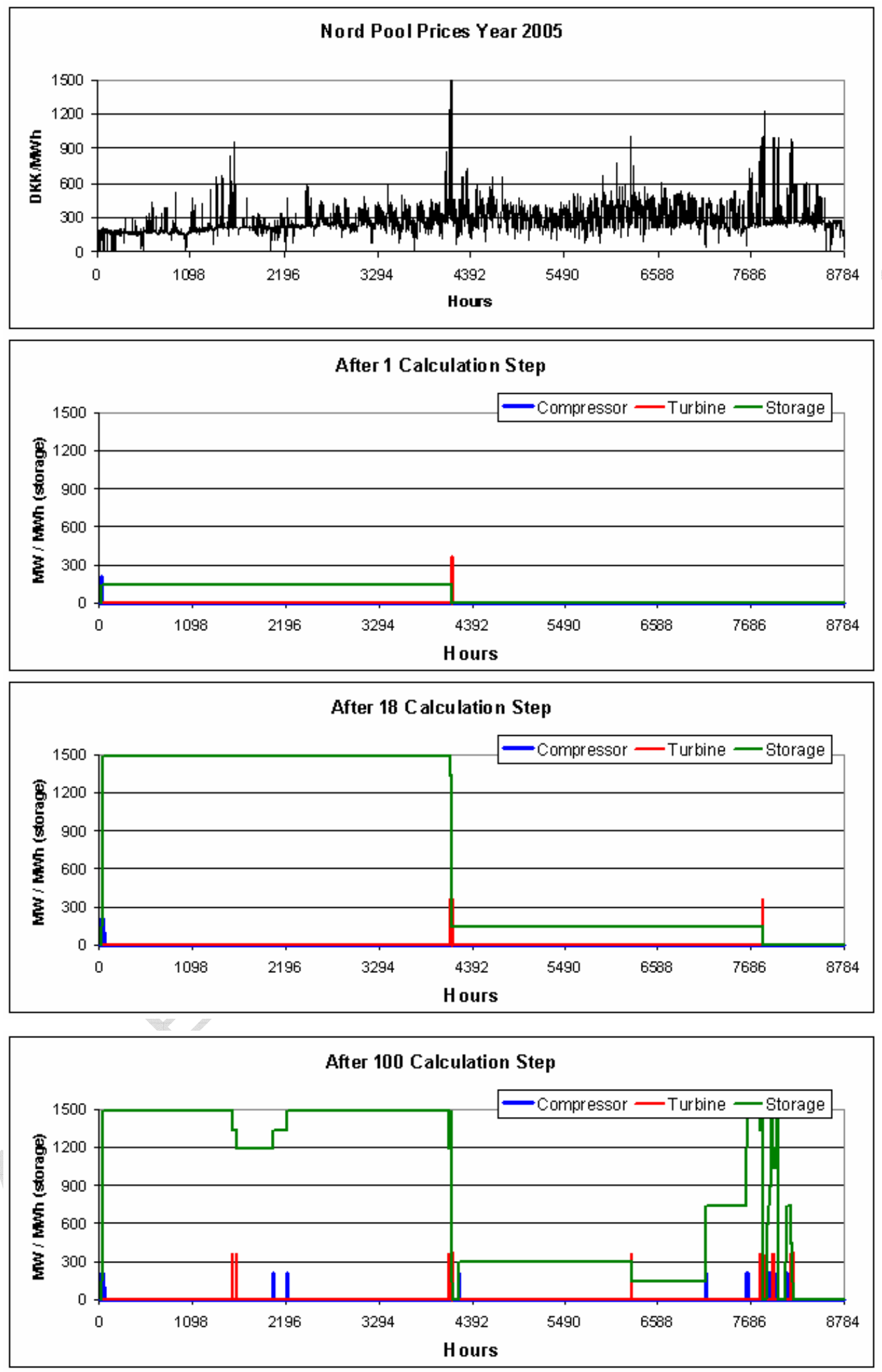

Figure 3: NordPool electricity prices for 2005 and CAES plant operation after various iterations in the EnergyPLAN strategy algorithm. 


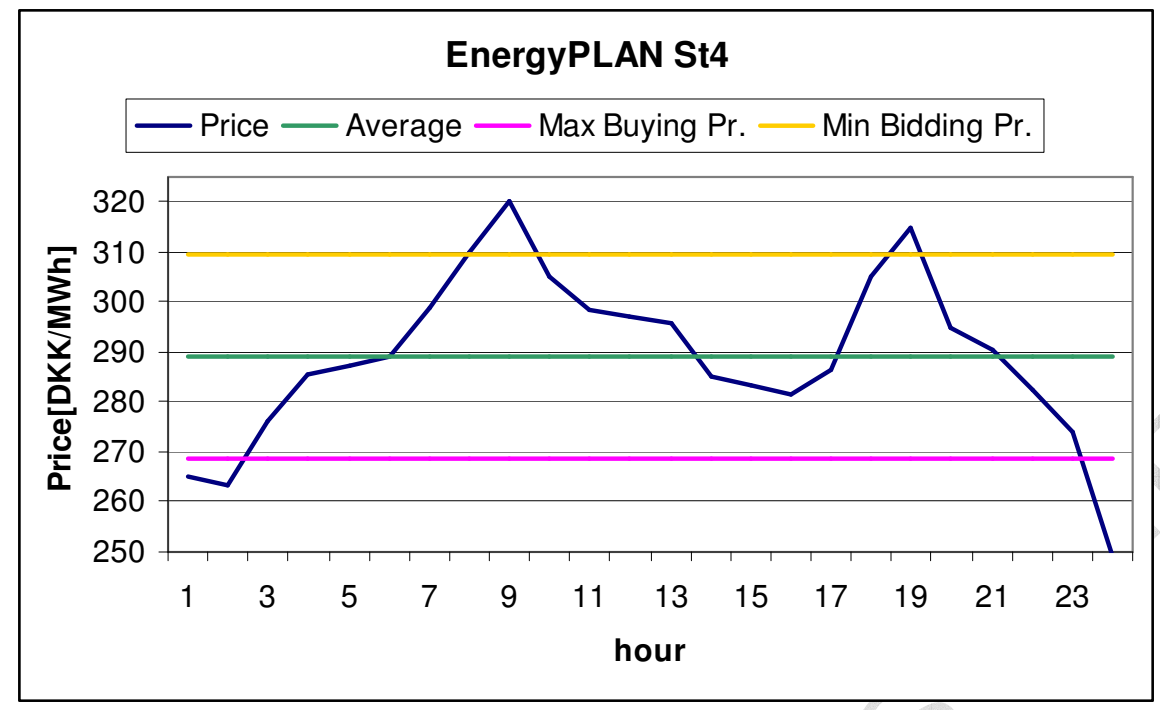

Figure 4: EnergyPLAN practical prognostic concept, where the average of an upcoming period, 24 hours in this figure, is used to calculate the market bidding prices. 


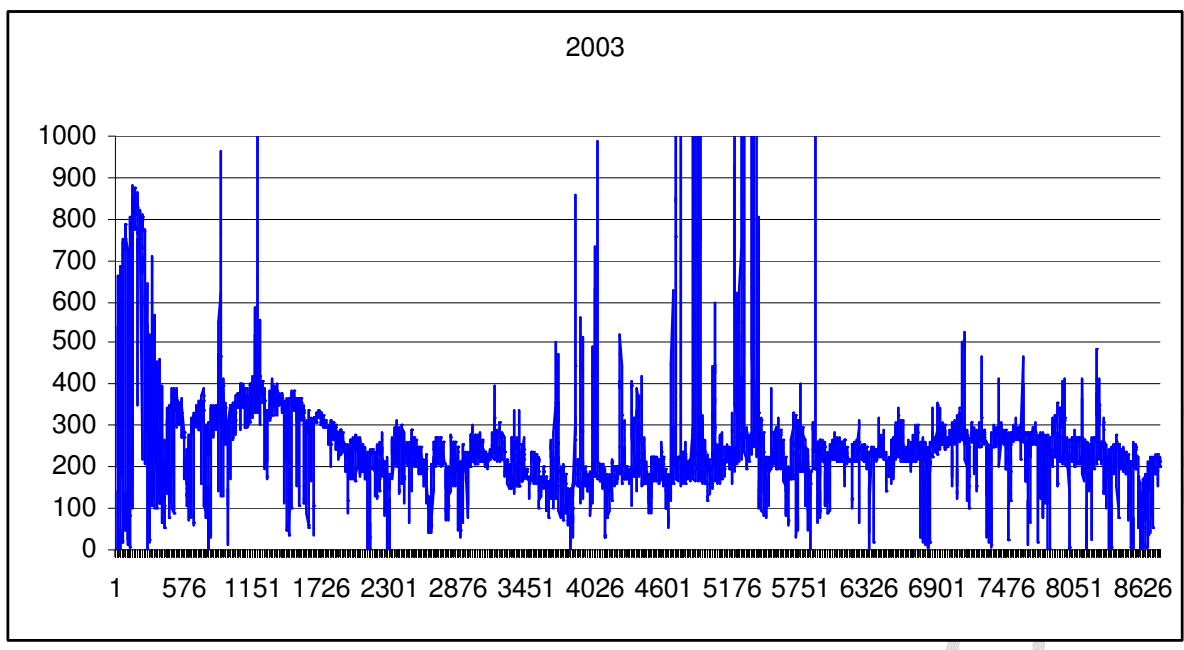

Figure 5: System prices for Western Denmark in 2003 (DKK pr MWh) 
Table 1

Input data for testing the optimisation strategies

CAES plant: Compressor Capacity $=214 \mathrm{MW}$

Turbine Capacity $=361 \mathrm{MW}$

Storage Capacity $=1480 \mathrm{MWh}$

Comp. Efficiency $=69.1 \%$

Fuel Ratio $=\frac{434 \text { MWh Fuel }}{361 \text { MWh El Out }}=1.202$

Turbine Efficiency $=\frac{361 \mathrm{MWh} \text { El Out }}{\text { CompCap } \times \text { CompEfficency }}=2.441$

Compressor variable Cost $=17 \mathrm{DKK} / \mathrm{MWh}(2.3 \mathrm{EUR} / \mathrm{MWh})$

Turbine variable Cost $=20 \mathrm{DKK} / \mathrm{MWh}$ (2.7 EUR/MWh)

Economy: $\quad$ Electricity Price Time Series $=2003$ DK West Spot Prices

Natural Gas Price $=100$ DKK/MWh 
Table 2

Results of testing the optimisation strategies

\begin{tabular}{|c|c|c|c|}
\hline Million DKK & $\begin{array}{l}\text { Dynamic } \\
\text { programming }\end{array}$ & $\begin{array}{l}\text { Plant optimisation } \\
\text { energyPRO tool }\end{array}$ & $\begin{array}{l}\text { Energysyst. analysis } \\
\text { EnergyPLAN tool }\end{array}$ \\
\hline $\begin{array}{l}\text { Income: } \\
\text { Electricity sales }\end{array}$ & 244.72 & 244.72 & 244.72 \\
\hline $\begin{array}{l}\text { Cost: } \\
\text { Electricity } \\
\text { Compressor operation } \\
\text { Turbine operation } \\
\text { Natural gas }\end{array}$ & $\begin{array}{lr}- & 71.99 \\
- & 5.98 \\
- & 11.87 \\
- & 71.34\end{array}$ & $\begin{array}{lr}- & 71.99 \\
- & 5.98 \\
- & 11.87 \\
- & 71.34\end{array}$ & $\begin{array}{rr}- & 71.99 \\
- & 5.98 \\
- & 11.87 \\
- & 71.34\end{array}$ \\
\hline Sum & 83.539 & 83.539 & 83.539 \\
\hline
\end{tabular}


Table 3

Comparing practical optimisation strategies to the optimal strategy

\begin{tabular}{|c|c|c|c|}
\hline Million DKK & $\begin{array}{l}\text { Practical historic } \\
\text { strategy }\end{array}$ & $\begin{array}{l}\text { Practical prognostic } \\
\text { Strategy }\end{array}$ & $\begin{array}{l}\text { Theoretical optimal } \\
\text { Strategy }\end{array}$ \\
\hline \multicolumn{4}{|l|}{ Income: } \\
\hline Electricity sales & 215.62 & 225.42 & 244.72 \\
\hline \multicolumn{4}{|l|}{ Cost: } \\
\hline Electricity & 72.47 & 71.02 & 71.99 \\
\hline Compressor operation & 5.07 & $\begin{array}{l}-\quad 5.39\end{array}$ & 5.98 \\
\hline Turbine operation & - $\quad 10.06$ & 10.70 & 11.87 \\
\hline Natural gas & - $\quad 60.45$ & $-\quad 64.31$ & 71.34 \\
\hline Sum & 67.578 & 74.002 & 83.539 \\
\hline
\end{tabular}

